\title{
Tylosin Inhibited Growth of Chlorella Vulgaris and Raphidocelis Subcapitata by Inducing Oxidative Stress
}

\section{Denglong Lu}

Central South University

\section{Zhihua Ma}

Northwest University

Jianglin Peng

Northwest University

Yibo Zhang

Northwest University

Shan Liu

Northwest University

Qi Li ( $\square$ qili726@nwu.edu.cn )

Northwest University https://orcid.org/0000-0002-6370-9311

\section{Research Article}

Keywords: Tylosin, Chlorella vulgaris, Raphidocelis subcapitata, oxidative stress, antioxidant

Posted Date: June 14th, 2021

DOI: https://doi.org/10.21203/rs.3.rs-586561/v1

License: (1) This work is licensed under a Creative Commons Attribution 4.0 International License. Read Full License 


\section{Abstract}

Two model algae Chlorella vulgaris (C. vulgaris) and Raphidocelis subcapitata ( $R$. subcapitata) were generally used to test chemicals with antimicrobial properties during registration process. However, it has been reported that significant sensitivity difference in two algae when exposure to antibiotics. Furthermore, the selection of an appropriate test species play a vital role in evaluate of environmental hazards and risks of compounds. Since the balance between oxidative stress and antioxidant is a crucial factor on alga growth. This experiment is performed to investigate the working of oxidative stress and mechanism of antioxidant defense system of algae under antibiotic stress. A series of concentration of Tylosin (TYN), a macrolide antibiotic, were used to test in this study. Oxidative stress biomarkers (Malondialdehyde (MDA)), non-enzymatic antioxidants (Reduced glutathione (GSH)), antioxidant enzymes (Superoxide dismutase (SOD), Catalase (CAT), Glutathione Peroxidase (GP), Glutathione Stransferase (GST)) and photosynthetic pigments were measured to investigate antioxidant defense system. $R$. subcapitata was significantly inhibited with increasing concentration of TYN, whereas no effects on $C$. vulgaris. The contents of MDA increased significantly when species were inhibited, and thus, activating the antioxidant system, companying with the significantly increasing of SOD and CAT.

\section{Introduction}

Antibiotics are widely used in human and veterinary medicine for the therapeutic treatment of infectious diseases, as well as for farm animal feed additives for agricultural purposes (Boxall 2004; Kummerer 2009; Zhu and others 2013). China is the highest country of antibiotics consumption and production in the word (Liu and others 2019). In China, the total production of all antibiotics was estimated to be 248,000 tons in 2013 which almost tripled since 2009 and the usage was up to 162,000 tons, in which human consumption accounted for $48 \%$ and the rest was shared by animals (Liu and others 2018; Zhang and others 2015). Finally, 53,800 tons of antibiotics were emitted into the environment by kinds of wastewater treatments (Zhang and others 2015). The antibiotics consumed by human and veterinary are mainly excreted via urine and feces (Lienert and others 2007; Sarmah and others 2006), which most of these excretions are in unchanged and active forms (Hirsch and others 1999). Substantial antibiotic can lead to adversely impact humans and animals health (Durso and others 2012), also impacts on soil and sediment microbial communities (Rice 2009), damage to the ecosystem by affecting key species and spread antibiotic residues and antibiotic resistance in the environment (Choi and others 2008; Rice 2009).

Tylosin (TYN), a macrolide antibiotic, used as a as a veterinary prophylactic (for intestinal and respiration infections) and a growth additive to animal feed (Hagenbuch and Pinckney 2012; Kline and Pinckney 2016). It can affect binding to the $50 \mathrm{~S}$ ribosomal subunit by inhibiting the prokaryotic protein synthesis (Kline and Pinckney 2016). The concentration with 0.31-3.02 nmol L-1 and $2.84 \mathrm{nmol} \mathrm{kg}^{-1}$ of TYN in water and sediments had been reported, respectively (Calamari and others 2003; Halling-Sorensen 2000; Kim and Carlson 2007; Kolpin and others 2002). Besides, TYN also was demonstrated toxic to many phytoplankton species at near environmental concentrations level (Eguchi and others 2004; HallingSorensen 2000; Swenson and others 2012; Yang and others 2008). 
The existing studies had reported that, compared with fish (Crane and others 2006; Santos and others 2010), daphnia and crustacean (Isidori and others 2005), algal species, especially cyanobacteria (Lutzhoft and others 1999), exhibit higher sensitivity toward antibiotics. Moreover, the alga was primary producer status and had short generation times (Xiong and others 2016). Thus algae were recommended as the test species in the environmental risk assessment of antibiotics in the marketing authorization process, especially Blue-Green algal (cyanobacteria) species were preferred to be used when testing the toxicity of active ingredients with anti-microbial properties (EMA, 2018). Chlorella vulgaris (C. vulgaris) and Raphidocelis subcapitata (R. subcapitata) are two model species widely used in chemical test (OECD, $1984 ; 2011)$. However, there were significant difference in two algae when exposure to macrolide antibiotics, with the median effective concentration $\left(\mathrm{EC}_{50}\right)$ of $4.41 \mathrm{and}>86.57 \mathrm{mg} \mathrm{L}^{-1}$ respectively, TYN for instance (Guo and others 2016). And the selection of an appropriate test species play a vital role in evaluate of environmental hazards and risks of compounds. Thus, it is necessary to evaluate the sensitivity of two algae when exposure to antibiotics.

In the plants, the stress environmental conditions can lead to the generation of reactive oxygen species (ROS), including hydrogen peroxide, singlet oxygen, peroxide, hydroxyl and superoxide radicals (Alscher and others 1997). The stress-induced ROS can cause damage to lipids, proteins and DNA, ultimately resulting into accelerating cell senescence and cell death (Alscher and others 1997). Malondialdehyde (MDA) is an indicator of lipid peroxidation contents which used to assess oxidative stress in the cells (Polle and others 1997). The accumulated ROS can be counteracted by enzymatic antioxidant (Superoxide dismutase (SOD), Catalase (CAT), Glutathione Peroxidase (GP) activities Glutathione Stransferase (GST)) and non-enzymatic antioxidant (Reduced glutathione (GSH) and photosynthetic pigments) (Kurade and others 2016). For example, after 7 day exposure, erythromycin at the concentration levels of 40 and $60 \mathrm{~g} \mathrm{~L} \mathrm{~L}^{-1}$ significantly increased the content of MDA in $R$. subcapitata along with the inhibition of growth; the activity of superoxide dismutase (SOD) and catalase (CAT) were correspondingly elevated ( $\mathrm{Ma}$ and others 2021). Chlorophyll and carotenoids in plant cells also have antioxidant properties, in order to reduce or avoid the damage of photosynthetic system induced by oxidative stress. In R. subcapitata, 4 days of exposure to $19.4 \mathrm{mg} \mathrm{L}^{-1}$ TYN significantly elevated the total chlorophyll and carotenoid contents (Guo and others 2016). However, there are few systematic studies on the effect of TYN on ROS production and antioxidant response of $C$. vulgaris and $R$. subcapitata, and the role of oxidative stress in observing species sensitivity.

In this study, two model algae $C$. vulgaris and $R$. subcapitata were tested in TYN contaminants to evaluate the sensitivity. The two algae were compared systematically effected by TYN. The endpoint used in the assessment included cells number, pH, MDA, SOD, CAT, GSH, GST, GP and photosynthetic pigments (total chlorophyll and carotenoids). The results of this study revealed the role of oxidative stress in the algal species sensitivity towards TYN exposure.

\section{Materials And Methods}

2.1 Chemicals 
Tylosin Tartrate (CAS no.1405-54-5; HPLC $\geq 98.0 \%$ ) was purchased from Shanghai yuanye BioTechnology Co., Ltd (Shanghai CHN). Erythromycin-13C, d3 (CAS no. 959119-26-7; HPLC $\geq 99 \%$ ) and atrazine D5 (CAS no. 1912-24-9; HPLC $\geq 97.0 \%$ ) were purchased from J\&K Scientific (Beijing, CHN). Methanol and acetonitrile with HPLC $\geq 99.9 \%$ were obtained from TEDIA (Ohio, USA). Formic acid (HPLC $\geq 88 \%$ ) was purchased from Kemiou Chemical Reagent Co., Ltd (Tianjin, CHN). Biomarker kits for the determination of SOD, CAT, GP and the content of MDA, GSH, GST were purchased from the Nanjing Jiancheng Co., Ltd. (Nanjing, CHN). Other chemicals used in this study were at least reagent grade.

\subsection{Algal cultures}

Algal toxicity tests were conducted using organisms, C. vulgaris (FACHB-8) and $R$. subcapitata (FACHB271), obtained from Freshwater Algae Culture Collection at the Institute of Hydrobiology (Wuhan, China). Algae culture was performed following the existed Guideline. In brief, both of algae were grown in BlueGreen Medium (BG11), pH 7.1 (OECD, 2011). C. vulgaris and R. subcapitata were cultured in $250 \mathrm{~mL}$ Erlenmeyer flasks containing $150 \mathrm{~mL} \mathrm{BG} 11$ with a controlled temperature $\left(22 \pm 2{ }^{\circ} \mathrm{C}\right)$ and constant illumination (5500 Lux). The initial algal concentrations for $C$. vulgaris and $R$. subcapitata were set at $2 \times$ $10^{4}$ cells $\mathrm{mL}^{-1}$ and $1 \times 10^{4}$ cells $\mathrm{mL}^{-1}$, respectively. By the way, the Erlenmeyer flasks gently shaken manually three times per day. All glassware, stoppers and inoculum used in this study were autoclaved at $121^{\circ} \mathrm{C}$ for $30 \mathrm{~min}$ and all the operations were performed on a clean bench. According to the guidelines (OECD 1984; 2011), the algal suspension, at its exponential phase, was used for further experiments. The cell density was estimated by counting the cell number with a hemacytometer under a microscope, on a daily basis, to plot the growth curve (cell density versus day). The algal stocks were subcultured each week.

\subsection{Procedures for the growth inhibition test}

The growth inhibition tests for TYN was conducted on the basis of OECD Guidelines. ${ }^{30}$ In order to determine the concentration of TYN during the experiment, we initially measured $\mathrm{EC}_{50} \mathrm{~s}$ for $C$. vulgaris and $R$. subcapitata by plotting the concentration-response curves. Specifically, $C$. vulgaris and $R$. subcapitata were exposed to different concentrations of TYN (C. vulgaris: $0,0.5,1,1.5,3$, and $5 \mathrm{mg} \mathrm{L}^{-1} ; R$. subcapitata: $0,0.2,0.45,0.8,1.6$, and $3.2 \mathrm{mg} \mathrm{L}^{-1}$ ) and cultured for 4 days. On day 4, the 4-day $\mathrm{EC}_{50} \mathrm{~s}$ of TYN against both species of algae was calculated by the cell densities of $C$. vulgaris and $R$. subcapitata. In this study, the 4-day $\mathrm{EC}_{50}$ of TYN for $R$. subcapitata was $0.75 \mathrm{mg} \mathrm{L}^{-1}$ (Figure S1), however, TYN could not significantly inhibit the growth of $C$. vulgaris, the 4-day $\mathrm{EC}_{50}$ of TYN for $C$. vulgaris was not calculated. According to $\mathrm{EC}_{50}$ s value in this study and the value reported in previous study (Table S3), we determined the concentration of TYN in the experiment. The toxicological effects of same concentrations of $\operatorname{TYN}\left(0,0.003,0.8,1.2,1.6\right.$ and $\left.3 \mathrm{mg} \mathrm{L}^{-1}\right)$ on $R$. subcapitata and $C$. vulgaris were investigated by cultivating the same initial algal biomass as above in $250 \mathrm{~mL}$ Erlenmeyer flasks containing $150 \mathrm{~mL}$ of sterilized BG11 for 7 days. Each concentration was conducted in triplicates. The cell numbers were measured at regular time intervals $(2,4$, and 7 days). 
MDA, SOD, GP, GST, CAT and GSH were measured according to the manufacturer's protocol (Nanjing Jiancheng Bioengineering Institute, China) after 7-days exposure. As for the high inhibition at the TYN concentration of 1.6 and $3 \mathrm{mg} \mathrm{L}^{-1}$ on $R$. subcapitata, only the oxidative stress biomarkers of $0,0.003,0.8$ and $1.2 \mathrm{mg} \mathrm{L}^{-1}$ were measured. In this study, $5 \mathrm{~mL} R$. subcapitata culture at the concentration of 0 and $0.003 \mathrm{mg} \mathrm{L}^{-1}$ and $50 \mathrm{~mL}$ for 0.8 and $1.2 \mathrm{mg} \mathrm{L}^{-1}$ respectively were harvested at day 7 by centrifugation at $4000 \mathrm{rpm} \mathrm{min}{ }^{-1}$ for $10 \mathrm{~min}$ in the centrifuge tubes. Meanwhile $5 \mathrm{~mL} \mathrm{C}$. vulgaris culture was harvested by the same method. And the centrifugation was weighted again after the supernatant was discarded which was used to calculated the algae wet weight. Then the precipitates was re-suspended by $1 \mathrm{~mL}$ strokephysiological saline solution (SPSS) into the centrifuge tubes and centrifuged at $1000 \mathrm{rpm} \mathrm{min} \mathrm{for}^{-10}$ min. This process repeated three times. The precipitates was re-suspended by $2 \mathrm{~mL} \mathrm{SPSS}$ at the last time the supernatant was discarded. Then the suspension homogenated in ice water bath for six times (one time per minutes, 30 seconds interval) with a tissue tearor. Then the suspension was used to measure the oxidative stress biomarkers following the protocol. The activity or contents of these biomarkers were measured with a Tecan Infinite ${ }^{\circledR} 200$ Pro multi-function microplate reader (Tecan Austria Gmbh, Männedorf, Switzerland).

2.5 Measurement of total chlorophyll and carotenoid content

The chlorophyll $a, b$ and carotenoid content were measured following the previous study. ${ }^{37}$ After 7-days exposure in the growth studies, $5 \mathrm{~mL}$ microalgal suspensions from each sample were filtered using a $0.22-\mu \mathrm{m}$ fiber filter. Then each filter membrane put into a $5 \mathrm{~mL}$ centrifuge tube containing $3 \mathrm{~mL}$ methanol to extract pigments in a spark free fridge $\left(-80^{\circ} \mathrm{C}\right)$ for $24 \mathrm{~h}$. All samples were centrifuged at $10,000 \mathrm{rpm}$ $\mathrm{min}^{-1}$ for $10 \mathrm{~min}$. Chlorophyll a and b were estimated using the Wellburn coefficient equation (Equation1; Equation2) (Wellburn 1994) and the carotenoid were estimated using the Lichtenthaler equation (Equation3). Absorbance values $\left(A_{470}, A_{653}\right.$, and $\left.A_{666}\right)$ were measured by Tecan Infinite ${ }^{\circledR} 200$ Pro Mutil Reader.

Chlorophylla $\left(\mathrm{mgL}^{-1}\right)=15.65 \mathrm{~A}_{666}-7.34 \mathrm{~A}_{653}$

(Equation1)

Chlorophyllb $\left(\mathrm{mgL}^{-1}\right)=27.05 \mathrm{~A}_{653}-11.21 \mathrm{~A}_{666}$

(Equation2)

Carotenoids $\left(\mathrm{mgL}^{-1}\right)=\left(1000 \mathrm{~A}_{470}-44.76 \mathrm{~A}_{666}\right) \div 221$

(Equation3)

\subsection{Antibiotic analysis}

At day 0 , The concentrations of TYN in all samples were determined using liquid chromatography tandem-mass spectrometry (LC-MS/MS, Agilent 1290) coupled with solid phase extraction (SPE). Details 
on the system settings and method validation can be found in Supporting Information. Since the variation between the nominal and measured concentrations was less than $20 \%$, the nominal concentration was used for further investigation (OECD, 2011).

\subsection{Statistical methods}

The experimental data was analyzed by using The GraphPad Prism 8.0 software (California, USA). The normality test of MDA content, GSH content, antioxidant enzyme activities, $\mathrm{pH}$ and pigment contents were determined using the Normality and Lognormality Tests. Further more significant differences between in treatments and controls were calculated using the one way ANOVA Dunnett test. A $p$ value less than 0.05 was considered statistically significant.

\section{Results And Discussion}

\section{1 $\mathrm{pH}$ value and effects of TYN on the algal growth}

The pH values of $R$. subcapitata significantly decreased by $17 \%$ and $19 \%$ at the TYN concentration of 0.8 and $1.2 \mathrm{mg} \mathrm{L}^{-1}$ compared to controls (Fig. 1). By the way, the $\mathrm{pH}$ values of $C$. vulgaris of treatments almost have nothing changed after 7 days exposure compared with controls. However, the $\mathrm{pH}$ values of all controls and treatments of were increased that from 7.1 to 10.2 for $C$. vulgaris and 7.1 to 7.6 for $R$. subcapitata, respectively. The results were also agreed with the previous study that the low $\mathrm{pH}$ increased for species because of their relatively low growth rates compared with others and the $\mathrm{pH}$ values always increased in an algal toxicity test for $\mathrm{CO}_{2}$ was derived from biocarbonate in the medium to meet carbon demand of algal growth (Halling-Sorensen 2000; Lutzhoft and others 1999). The curves of R. subcapitata and $C$. vulgaris are plotted when expose to the same TYN concentration for 7 days (Fig. 2). As for $C$. vulgaris, all the selected TYN concentrations have no inhibition between treatments and controls. And $C$. vulgaris have a rapid growth from 2 to 7 days. $R$. subcapitata is almost completely inhibited at the concentration of $1.2,1.6$ and $3 \mathrm{mg} \mathrm{L}^{-1}$ and also significant inhibition by $83 \%(p<0.05)$ at the concentration of $0.8 \mathrm{mg} \mathrm{L}^{-1}$. Both of the environmental correlation concentrations $\left(0.003 \mathrm{mg} \mathrm{L}^{-1}\right)$ of $R$. subcapitata and $C$. vulgaris have the same growth rate compared with controls (Fig. 2).

\subsection{Effects of TYN on the biochemical characteristics of algae species}

\subsubsection{Effect of TYN on MDA and antioxidant enzymes}

The environmental stress conditions such as environmental contaminants, UV-radiation, high temperature, salinity and others cause reactive oxygen species (ROS) to accumulate (Kanerva 2014; Pancha and others 2015). The oxidative stress of ROS may cause the damage of cell membrane, chloroplast, mitochondria and other organelles, and then inhibit the physiological activities such as growth and photosynthesis (Ke and others 2010). ROS can influence the expression of genes and signal transduction pathway (Allen 1998), which also were subcellular messengers for certain growth factors (Wagner 1995). ROS cause damage to cellular organelles by peroxidizing polyunsaturated fatty acids 
(PUFA) whose representative product is MDA, an aldehyde (Xiong and others 2017a). In this study, the MDA contents of $R$. subcapitata increased by 3.7 and 1.7 folds at TYN concentrations of 0.8 and $1.2 \mathrm{mg}$ $\mathrm{L}^{-1}$ compared with controls, respectively (Fig. 3). The MDA contents also have a low increased at TYN concentrations of $0.003 \mathrm{mg} \mathrm{L}^{-1}$ which have a little inhibition on algal growth (Fig. 3). The previous study reported that the MDA production in Chlamydomonas reinhardti cells increased significantly with increasing Saxitoxin concentrations (Melegari and others 2012). As for C. vulgaris, the MDA contents increased by $28 \%$ at the environmental concentration compared with controls (Fig. 3). Besides, the MDA contents increased with the concentration increasing of other treatments and all of them lower than controls (Fig. 3). The results also agreed with the study that Microcystis flos-aquae exposed to levofloxacin (Wan and others 2014). All the changes of MDA contents of $C$. vulgaris showed no significant differences. The significant increase of MDA content might indicate the sensitivity of $R$. subcapitat to other $C$. vulgaris. Stress-induced ROS accumulation is offset by an enzymatic antioxidant system, which includes various scavengers, such as SOD, CAT, GP, GST and GSH (Mittler and others 2004).

In order to cope with excessive ROS and the production of lipid peroxides and other oxides, a series of enzymes including SOD and cat are involved in the elimination of ROS (Apel and Hirt 2004). SOD is an antioxidative enzyme that provides the first line of defense against ROS toxicity which can catalyzethe dismutation of $\mathrm{O}_{2}{ }^{-1}$ to $\mathrm{H}_{2} \mathrm{O}_{2}$ and $\mathrm{O}_{2}$ (Xiong and others 2017a). $\mathrm{H}_{2} \mathrm{O}_{2}$ is decomposed to $\mathrm{H}_{2} \mathrm{O}$ by CAT and the peroxidases (such as GP) (Kanerva 2014). GSH can react with ROS independently apart from its role as a substrate for GST and GP (Kanerva 2014). Therefore, it is crucial to evaluate the sensitivity of the two model algae which used for chemical test and explore the antioxidant defense system when exposure in TYN. CAT catalyze the conversion of $\mathrm{H}_{2} \mathrm{O}_{2}$ into $\mathrm{H}_{2} \mathrm{O}$ and $\mathrm{O}_{2}$, thereby reducing the oxidation damage caused by $\mathrm{H}_{2} \mathrm{O}_{2}$ (Wan and others 2014). The SOD activity of $R$. subcapitata showed no significant difference with the control at environmental concentration levels of TYN exposure, whereas TYN at concentration of 0.8 and $1.2 \mathrm{mg} \mathrm{L}^{-1}$ could significantly stimulate the SOD activity, which increased to 23.38 and 18.87 times the control, respectively (Fig. 3). The CAT activities in $R$. subcapitata also showed a significantly increase of 2.85 times and 3.24 times relative to the control at the TYN concentration of 0.8 and $1.2 \mathrm{mg} \mathrm{L}^{-1}$, respectively (Fig. 3). The increased activity of CAT and SOD were likely attributed to the increase of MDA contents. The results were in agreement with the previously reported SOD and CAT activities of microalga Microcystis flos-aquae exposed to levofloxacin and Microcystis flos-aquae exposure to erythromycin (Ma and others; Wan and others 2015; Wan and others 2014). The SOD and CAT activity of $R$. subcapitata also showed a positive correlation with the test concentrations of TYN which similar with Microcystis aeruginosa exposure to amoxicillin (Liu and others 2012). However, the SOD and CAT activity of C.vulgaris decreased at the environmental concentration firstly from 2 times of controls, and then increased with the TYN concentration increased at $1.2 \mathrm{mg} \mathrm{L}^{-}$ ${ }^{1}$ (Fig. 3). All the changes of CAT and SOD of $C$. vulgaris had no significant. The activation of antioxidant responses is mediated partially through NF-kB (Allen and Tresini 2000), which involved in the regulation 
of numerous genes, including acute phase proteins, cell surface receptors, and cytokines; they also regulate certain viral genes (Roulston and others 1995).

GST play an important role in protecting plants against xenobiotics and ROS damage (Foyer and others 1997; Nemat Alla 1995). As a peroxidase, GST can also detoxify directly with electrophilic groups by binding to GSH (Alla and Hassan 2006). In the present study, the GST activity of $R$. subcapitata increased significantly 4.5 times induced by TYN at the concentration of $0.8 \mathrm{mg} \mathrm{L}^{-1}$, and 3.79 times at $1.2 \mathrm{mg} \mathrm{L}^{-}$ ${ }^{1}$ compared with control (Fig. 3). whereas, the GST activity of C.vulgaris have nothing changes. Thus, it was suggested that the increased activity of GST was attributed to scavenge the increased MDA by binding to GSH, as the same changes as the SOD and CAT. GSH can react with ROS independently apart from its role as a substrate for GST and GP (Kanerva 2014). Once activated, the protein reduces ROS production and stimulates GSH synthesis which results the activation of nf-kb was decreased by oxidant (Mehlen and others 1996). The GP transformed $\mathrm{H}_{2} \mathrm{O}_{2}$ to $\mathrm{H}_{2} \mathrm{O}$ and $\mathrm{O}_{2}$ by oxidizing glutathione (Kanerva 2014). Since the slight increase of GP in $R$. subcapitata may be used to scavenge excess $\mathrm{H}_{2} \mathrm{O}_{2}$ transformed from SOD (Fig. 3). By the way the GSH content and GP activity might show the same trend in both algae which also can be inferred from the Fig. 3 .

\subsubsection{Effects of TYN on the total chlorophyll and carotenoid contents}

Photosynthesis is one of the essential processes to harvest light and to convert light energy into chemical energy in plants and photosynthetic organisms (Xiong and others 2017b). Chlorophylls and carotenoids play an important role in this process, including light harvesting, energy transfer and light energy conversion (Xiong and others 2017a; Xiong and others 2017b). Besides, the chlorophyll can also scavenge the accumulated ROS serve as a protective mechanism in chloroplasts (Kasahara and others 2002). Carotenoids protect photosynthetic apparatus by scavenge 0 to inhibit oxidative damage, quench triplet sensitizer and excited chlorophyll (Chl*) molecule to prevent the formation of ${ }^{1} \mathrm{O}_{2}$ (Mattos and Moretti 2015). Carotenoids are thought to be the first line of defense against chloroplast toxicity of the antioxidant (Triantaphylides and Havaux 2009). These roles serve as protective mechanisms in the photosynthetic system and algal growth (Jahns and Holzwarth 2012). There was no significant change was detected in this study in the contents of total chlorophyll and carotenoids in both algae (Fig. 4). The contents of total chlorophyll and carotenoids in $R$. subcapitata and $C$. vulgaris showed the same and trend (Fig. 4). The sight increase of two pigments in $R$. subcapitata at 0.8 and $1.2 \mathrm{mg} \mathrm{L}^{-1}$ TYN concentration might be used to scavenge the ROS as the significant increase of MDA. It was consistent with other study that the two pigments increased slightly in the low contaminants which can be only observed in the R. subcapitata and the alga was slightly inhibited. It may be the less MDA increased in the low contaminants concentration and chlorophylls and carotenoids mainly attributed to the photosynthesis. Overall, a diagram illustrating the TYN-altered production of ROS and the antioxidant responses in R. subcapitata was established (Fig. 5).

\section{Conclusions}


Overall, the reactive oxygen species induced in two algae when exposure in TYN and its antioxidant defense system was studied in this experiment. $R$. subcapitata was significantly inhibited, whereas had no effects on $C$. vulgaris at the same TYN level. The MDA contents in increased significantly together with the SOD and CAT which also increased significantly at high TYN level. All the MDA contents and antioxidant enzyme had nothing significant changes in $C$. vulgaris. The photosynthetic pigment contents increased slightly at TYN of concentration 0.8 and $1.2 \mathrm{mg} \mathrm{L}^{-1}$ and environment level. Those findings suggested that the antibiotics can stimulate cells to produce excessive ROS, resulting in the increasing of MDA content and activating the antioxidant system which play pivotal roles in the sensitivity of two algal species to macrolide antibiotic exposure.

\section{Declarations}

\section{Acknowledgement}

This work was funded by Key Research and Development Plan of Shaanxi Province [Grant Number No. 2020SF-387 and 2020SF-400], Ministry of Science and Technology of the People's Republic of China [Grant Number 2017YFC0404303] and Scientific Research Foundation of the Water Conservancy Department of Shaanxi Province [Grant Number 2020slkj-13].

\section{Author contributions}

Qi Li: Conceptualization, Methodology, Writing - Original Draft, Project administration, Funding acquisition. Denglong Lu: Formal analysis, Investigation, Data Curation, Writing - Original Draft. Zhihua Ma, Jianglin Peng, Yibo Zhang, Shan Liu: Writing - Review \& Editing.

\section{Compliance with ethical standards}

Informed consent: All authors consent their participation.

Ethical approval: This article does not contain any studies with human

participants or animals performed by any of the authors.

Publisher's note: Springer Nature remains neutral with regard to jurisdictional claims in published maps and institutional affiliations.

\section{References}

1. Alla MN, Hassan N. 2006. Changes of antioxidants levels in two maize lines following atrazine treatments. Plant Physiology and Biochemistry 44(4):202-210.

2. Allen RG. 1998. Oxidative stress and superoxide dismutase in development, aging and gene regulation. Age 21(2):47-76. 
3. Allen RG, Tresini M. 2000. Oxidative stress and gene regulation. Free Radical Biology and Medicine 28(3):463-499.

4. Alscher RG, Donahue JL, Cramer CL. 1997. Reactive oxygen species and antioxidants: Relationships in green cells. Physiologia Plantarum 100(2):224-233.

5. Apel K, Hirt H. 2004. REACTIVE OXYGEN SPECIES: Metabolism, Oxidative Stress, and Signal Transduction. Annual Review of Plant Biology 55(1):373-399.

6. Boxall AB. 2004. The environmental side effects of medication. EMBO reports 5(12):1110-1116.

7. Calamari D, Zuccato E, Castiglioni S, Bagnati R, Fanelli R. 2003. Strategic survey of therapeutic drugs in the rivers Po and Lambro in northern Italy. Environmental Science \& Technology 37(7):1241-1248.

8. Choi K, Kim Y, Jung J, Kim MH, Kim CS, Kim NH, Park J. 2008. Occurrences and ecological risks of roxithromycin, trimethoprim, and chloramphenicol in the Han River, Korea. Environmental Toxicology and Chemistry: An International Journal 27(3):711-719.

9. Crane $M$, Watts $C$, Boucard T. 2006. Chronic aquatic environmental risks from exposure to human pharmaceuticals. Science of The Total Environment 367(1):23-41.

10. Durso LM, Miller DN, Wienhold BJ. 2012. Distribution and quantification of antibiotic resistant genes and bacteria across agricultural and non-agricultural metagenomes. PLoS One 7(11):e48325.

11. Eguchi K, Nagase H, Ozawa M, Endoh YS, Goto K, Hirata K, Miyamoto K, Yoshimura H. 2004. Evaluation of antimicrobial agents for veterinary use in the ecotoxicity test using microalgae. Chemosphere 57(11):1733-1738.

12. European Medicines Agency (EMA). 2018. "Guideline on the environmental risk assessment of medicinal products for human use." Available from: https://www.ema.europa.eu/en/documents/scientific-guideline/guideline-environmental-riskassessment-medicinal-products-human-use-first-version_en.pdf (accessed 15 August 2020).

13. Foyer CH, Lopez-Delgado H, Dat JF, Scott IM. 1997. Hydrogen peroxide-and glutathione-associated mechanisms of acclimatory stress tolerance and signalling. Physiologia Plantarum 100(2):241-254.

14. Guo J, Selby K, Boxall AB. 2016. Comparing the sensitivity of chlorophytes, cyanobacteria, and diatoms to major-use antibiotics. Environ Toxicol Chem 35(10):2587-2596.

15. Hagenbuch IM, Pinckney JL. 2012. Toxic effect of the combined antibiotics ciprofloxacin, lincomycin, and tylosin on two species of marine diatoms. Water Research 46(16):5028-5036.

16. Halling-Sorensen B. 2000. Algal toxicity of antibacterial agents used in intensive farming. Chemosphere 40(7):731-739.

17. Hirsch R, Ternes T, Haberer K, Kratz K-L. 1999. Occurrence of antibiotics in the aquatic environment. Science of the Total environment 225(1-2):109-118.

18. Isidori M, Lavorgna M, Nardelli A, Pascarella L, Parrella A. 2005. Toxic and genotoxic evaluation of six antibiotics on non-target organisms. Science of the Total Environment 346(1-3):87-98.

19. Jahns P, Holzwarth AR. 2012. The role of the xanthophyll cycle and of lutein in photoprotection of photosystem II. Biochimica Et Biophysica Acta-Bioenergetics 1817(1):182-193. 
20. Kanerva M. 2014. The Role of Oxidative Stress in Environmental Responses of Fennoscandian Animals.

21. Kasahara M, Kagawa T, Oikawa K, Suetsugu N, Miyao M, Wada M. 2002. Chloroplast avoidance movement reduces photodamage in plants. Nature 420(6917):829-832.

22. Ke L, Luo L, Wang P, Luan T, Tam NF. 2010. Effects of metals on biosorption and biodegradation of mixed polycyclic aromatic hydrocarbons by a freshwater green alga Selenastrum capricornutum. Bioresour Technol 101(18):6961-72.

23. Kim S-C, Carlson K. 2007. Quantification of human and veterinary antibiotics in water and sediment using SPE/LC/MS/MS. Analytical and Bioanalytical Chemistry 387(4):1301-1315.

24. Kline A, Pinckney JL. 2016. Size-selective toxicity effects of the antimicrobial tylosin on estuarine phytoplankton communities. Environmental Pollution 216:806-810.

25. Kolpin DW, Furlong ET, Meyer MT, Thurman EM, Zaugg SD, Barber LB, Buxton HT. 2002.

Pharmaceuticals, hormones, and other organic wastewater contaminants in US streams, 1999-2000: A national reconnaissance. Environmental Science \& Technology 36(6):1202-1211.

26. Kummerer K. 2009. Antibiotics in the aquatic environment - A review - Part I. Chemosphere 75(4):417-434.

27. Kurade MB, Kim JR, Govindwar SP, Jeon B-H. 2016. Insights into microalgae mediated biodegradation of diazinon by Chlorella vulgaris : Microalgal tolerance to xenobiotic pollutants and metabolism. Algal Research 20:126-134.

28. Lienert J, Gudel K, Escher BI. 2007. Screening method for ecotoxicological hazard assessment of 42 pharmaceuticals considering human metabolism and excretory routes. Environmental science \& technology 41(12):4471-4478.

29. Liu XH, Lu SY, Guo W, Xi BD, Wang WL. 2018. Antibiotics in the aquatic environments: A review of lakes, China. Science of the Total Environment 627:1195-1208.

30. Liu Y, Guan Y, Gao B, Yue Q. 2012. Antioxidant responses and degradation of two antibiotic contaminants in Microcystis aeruginosa. Ecotoxicology And Environmental Safety 86:23-30.

31. Liu Y, Liu X, Zhang G, Ma T, Du T, Yang Y, Lu S, Wang W. 2019. Adsorptive removal of sulfamethazine and sulfamethoxazole from aqueous solution by hexadecyl trimethyl ammonium bromide modified activated carbon. Colloids and Surfaces A: Physicochemical and Engineering Aspects 564:131-141.

32. Lutzhoft $\mathrm{HCH}$, Halling-Sorensen B, Jorgensen SE. 1999. Algal toxicity of antibacterial agents applied in Danish fish farming. Archives of Environmental Contamination and Toxicology 36(1):1-6.

33. Ma Z, Yang F, Ren J, Fan R, Duan Q, Guo J, Guo J. Growth Inhibition and Oxidative Stress in Two Green Algal Species Exposed to Erythromycin. JAWRA Journal of the American Water Resources Association $\mathrm{n} / \mathrm{a}(\mathrm{n} / \mathrm{a})$.

34. Mattos LM, Moretti CL. 2015. Oxidative stress in plants under drought conditions and the role of different enzymes. Enzyme Engineering 5:1-6. 
35. Mehlen P, Kretz-Remy C, Preville X, Arrigo A-P. 1996. Human hsp27, Drosophila hsp27 and human alphaB-crystallin expression-mediated increase in glutathione is essential for the protective activity of these proteins against TNFalpha-induced cell death. The EMBO journal 15(11):2695-2706.

36. Melegari SP, Perreault F, Moukha S, Popovic R, Creppy EE, Matias WG. 2012. Induction to oxidative stress by saxitoxin investigated through lipid peroxidation in Neuro $2 \mathrm{~A}$ cells and Chlamydomonas reinhardtii alga. Chemosphere 89(1):38-43.

37. Mittler R, Vanderauwera S, Gollery M, Van Breusegem F. 2004. Reactive oxygen gene network of plants. Trends in Plant Science 9(10):490-498.

38. Nemat Alla M. 1995. Glutathione regulation of glutathione S-transferase and peroxidase activity in herbicide-treated Zea mays. Plant physiology and biochemistry 33(2):185-192.

39. Pancha I, Chokshi K, Maurya R, Trivedi K, Patidar SK, Ghosh A, Mishra S. 2015. Salinity induced oxidative stress enhanced biofuel production potential of microalgae Scenedesmus sp. CCNM 1077. Bioresour Technol 189:341-348.

40. OECD. 1984. "Guideline for testing of chemicals: Alga, Growth Inhibition Test." Available from: https://www.oecd-ilibrary.org/environment/test-no-201-alga-growth-inhibition-test_9789264069923en (accessed 22 June 2020).

41. OECD. 2011. "Guideline for testing of chemicals: Freshwater Alga and Cyanobacteria, Growth Inhibition Test." Available from: https://www.ibacon.com/your-study-type/aquaticecotoxicology/aquatic-plants/oecd-201-freshwater-alga-and-cyanobacteria (accessed 22 June 2020).

42. Polle A, Eiblmeier M, Sheppard L, Murray M. 1997. Responses of antioxidative enzymes to elevated $\mathrm{CO} 2$ in leaves of beech (Fagus sylvatica L.) seedlings grown under a range of nutrient regimes. Plant, Cell \& Environment 20(10):1317-1321.

43. Rice LB. 2009. The clinical consequences of antimicrobial resistance. Current opinion in microbiology 12(5):476-481.

44. Roulston A, Lin R, Beauparlant P, Wainberg MA, Hiscott J. 1995. Regulation of human immunodeficiency virus type 1 and cytokine gene expression in myeloid cells by NF-kappa B/Rel transcription factors. Microbiol. Mol. Biol. Rev. 59(3):481-505.

45. Santos LHMLM, Araujo AN, Fachini A, Pena A, Delerue-Matos C, Montenegro MCBSM. 2010. Ecotoxicological aspects related to the presence of pharmaceuticals in the aquatic environment. Journal of Hazardous Materials 175(1-3):45-95.

46. Sarmah AK, Meyer MT, Boxall AB. 2006. A global perspective on the use, sales, exposure pathways, occurrence, fate and effects of veterinary antibiotics (VAs) in the environment. Chemosphere 65(5):725-59.

47. Swenson GJ, Hagenbuch IM, Pinckney JL, Long RA. 2012. Fluorometric estimation of surface associated microbial abundance. Journal of Microbiological Methods 88(2):297-303.

48. Triantaphylides C, Havaux M. 2009. Singlet oxygen in plants: production, detoxification and signaling. Trends in plant science 14(4):219-228. 
49. Wagner AM. 1995. A role for active oxygen species as second messengers in the induction of alternative oxidase gene expression in Petunia hybrida cells. Febs Letters 368(2):339-342.

50. Wan J, Guo P, Peng X, Wen K. 2015. Effect of erythromycin exposure on the growth, antioxidant system and photosynthesis of Microcystis flos-aquae. Journal of Hazardous Materials 283:778-786.

51. Wan J, Guo P, Zhang S. 2014. Response of the cyanobacterium Microcystis flos-aquae to levofloxacin. Environ Sci Pollut Res Int 21(5):3858-65.

52. Wellburn AR. 1994. The spectral determination of chlorophylls a and b, as well as total carotenoids, using various solvents with spectrophotometers of different resolution. Journal of plant physiology 144(3):307-313.

53. Xiong J-Q, Kurade MB, Abou-Shanab RAI, Ji M-K, Choi J, Kim JO, Jeon B-H. 2016. Biodegradation of carbamazepine using freshwater microalgae Chlamydomonas mexicana and Scenedesmus obliquus and the determination of its metabolic fate. Bioresource Technology 205:183-190.

54. Xiong JQ, Kurade MB, Kim JR, Roh HS, Jeon BH. 2017a. Ciprofloxacin toxicity and its co-metabolic removal by a freshwater microalga Chlamydomonas mexicana. J Hazard Mater 323(Pt A):212-219.

55. Xiong JQ, Miracle MB, Jeon BH. 2017b. Ecotoxicological effects of enrofloxacin and its removal by monoculture of microalgal species and their consortium. Environmental Pollution 226:486-493.

56. Yang L-H, Ying G-G, Su H-C, Stauber JL, Adams MS, Binet MT. 2008. Growth-inhibiting effects of 12 antibacterial agents and their mixtures on the freshwater microalga Pseudokirchneriella subcapitata. Environmental Toxicology and Chemistry 27(5):1201-1208.

57. Zhang Q-Q, Ying G-G, Pan C-G, Liu Y-S, Zhao J-L. 2015. Comprehensive Evaluation of Antibiotics Emission and Fate in the River Basins of China: Source Analysis, Multimedia Modeling, and Linkage to Bacterial Resistance. Environmental Science \& Technology 49(11):6772-6782.

58. Zhu S, Chen H, Li J. 2013. Sources, distribution and potential risks of pharmaceuticals and personal care products in Qingshan Lake basin, Eastern China. Ecotoxicology and Environmental Safety 96:154-159.

\section{Figures}




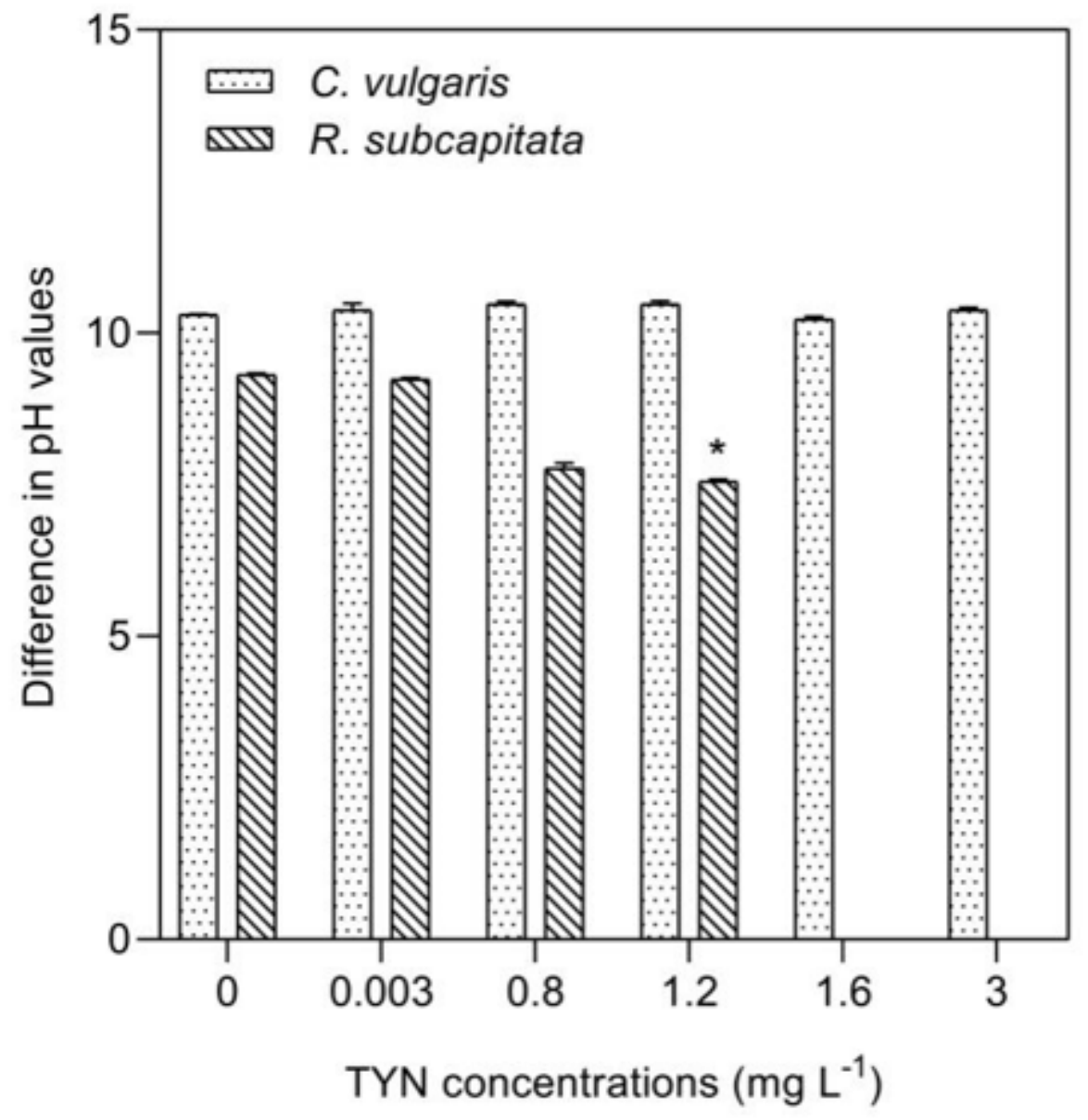

Figure 1

Changes in $\mathrm{pH}$ of R. subcapitata and $\mathrm{C}$. vulgaris during 7 days of exposure to TYN. Error bars represent standard deviation $(n=3)$. Columns with the symbol $(*)$ indicate significant differences $(p<0.05)$ between treatments and controls. 

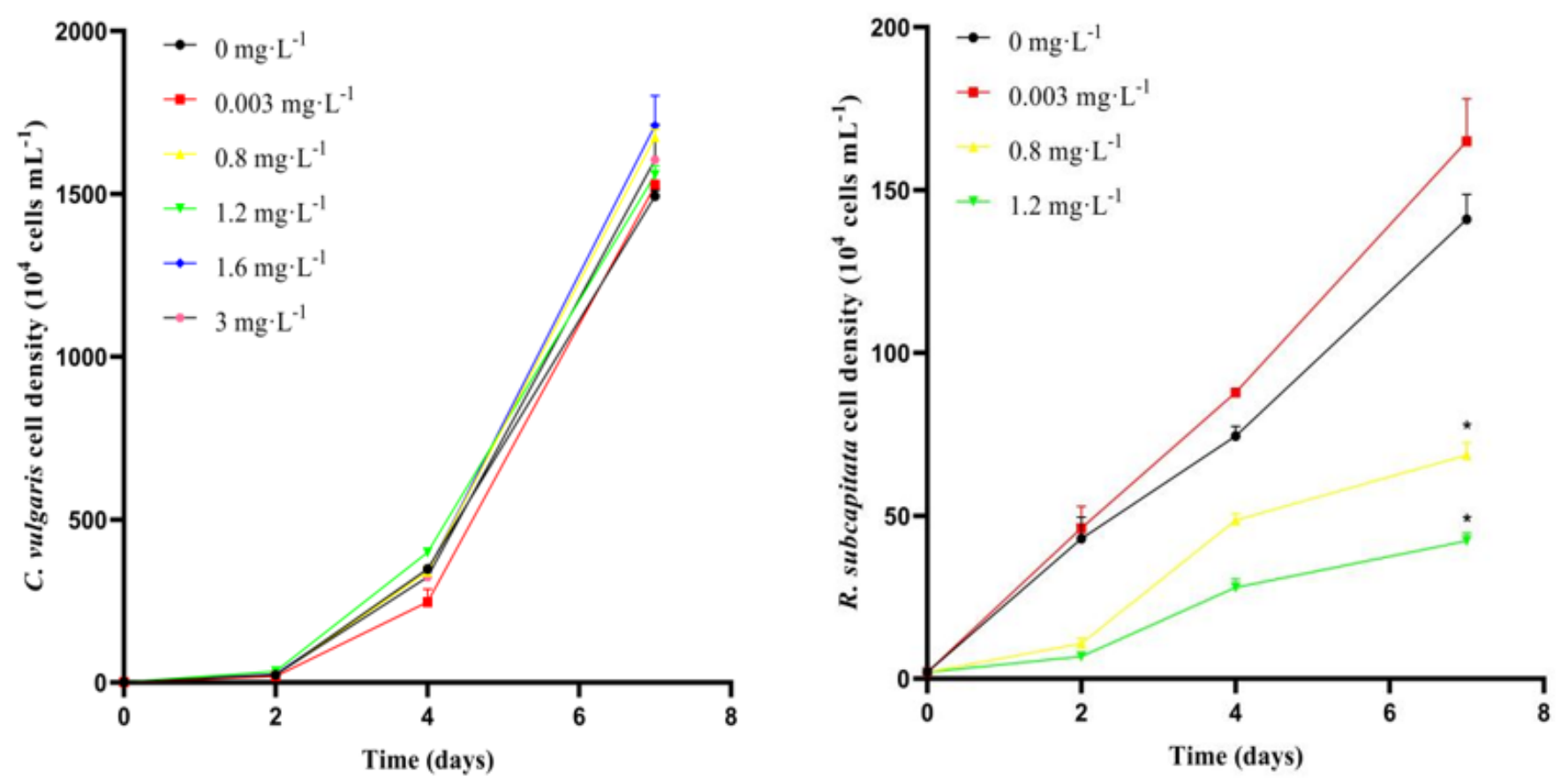

Figure 2

Effects of TYN on the growth of R. subcapitata and C. vulgaris during 7 days of cultivation. Error bars represent standard deviation $(n=3)$. Columns with the symbol $(*)$ indicate significant differences $(p<$ $0.05)$ between treatments and controls. 

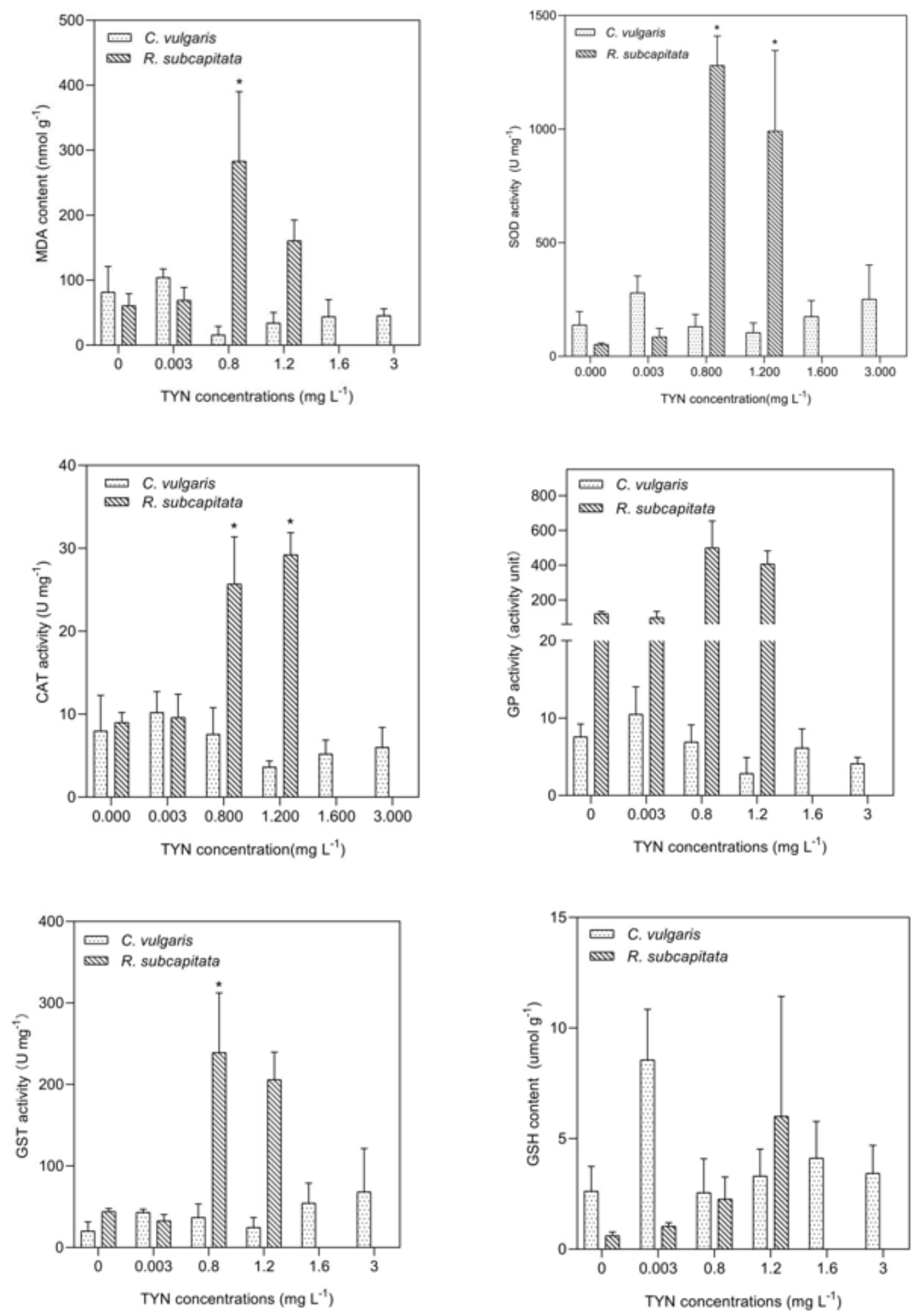

\section{Figure 3}

Diffidence effects of MDA (a), SOD (b), CAT (c), GP (d), GSH (e) and GST (f) on R. subcapitata and C. vulgaris at the same TYN concentrations. Error bars represent standard deviation $(n=3)$. Columns with the symbol $(*)$ indicate significant differences $(p<0.05)$ between treatments and controls. 

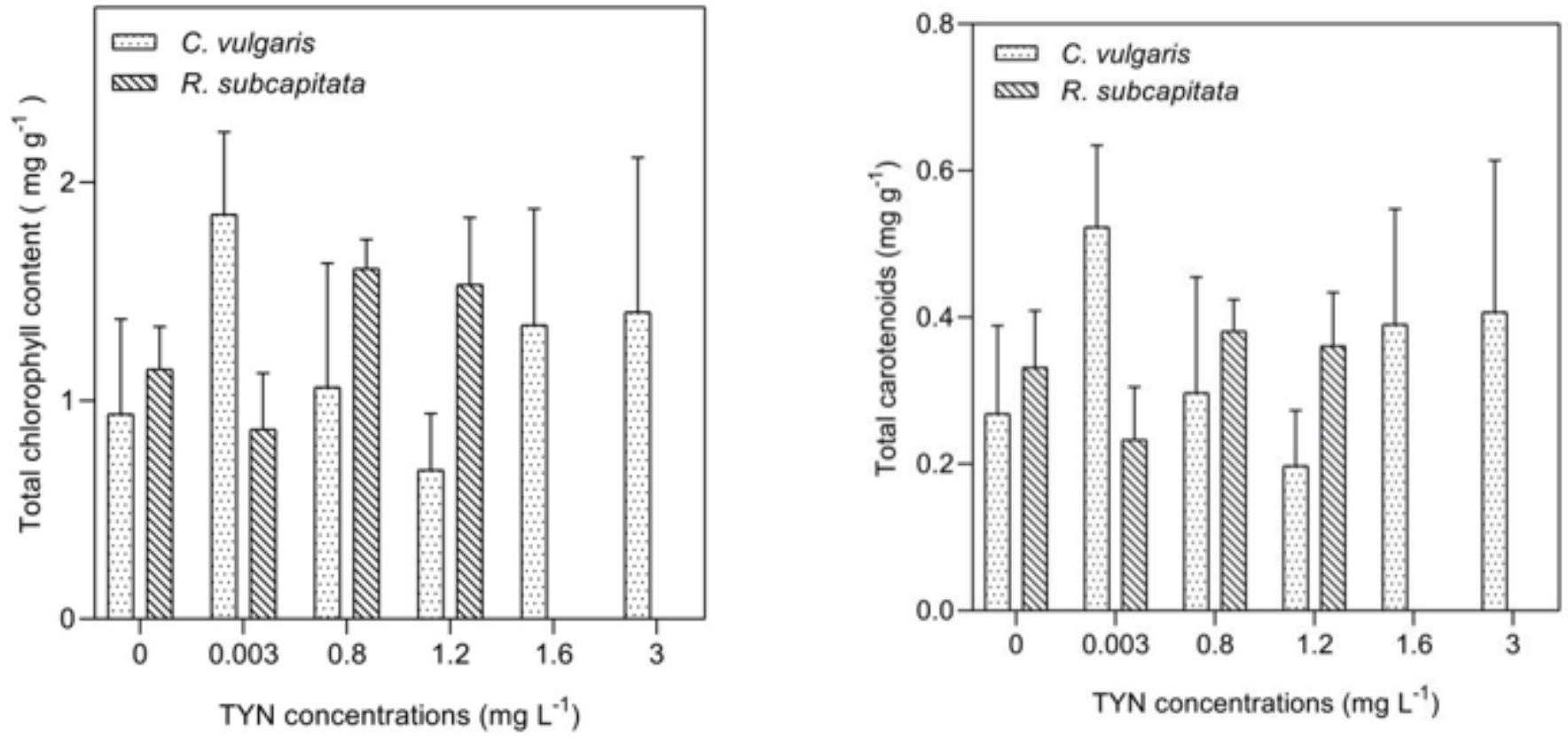

\section{Figure 4}

Total chlorophyll and carotenoid content of R. subcapitata and C. vulgaris after 7 days of cultivation. Error bars represent standard deviation $(n=3)$. Columns with the symbol $(*)$ indicate significant differences $(p<0.05)$ between treatments and controls.

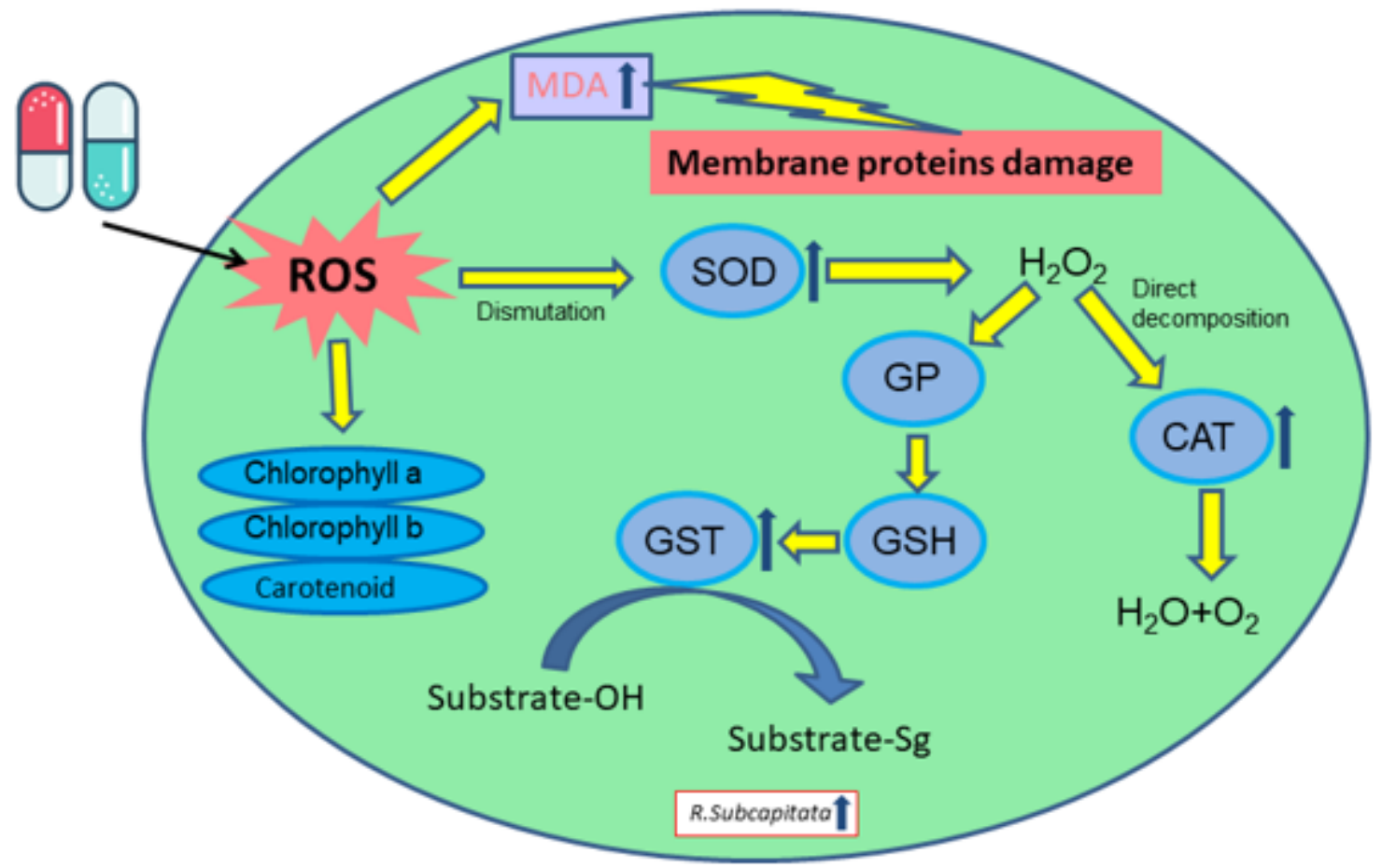

Figure 5 
TYN-altered production of ROS and the antioxidant defense system in R. subcapitata

\section{Supplementary Files}

This is a list of supplementary files associated with this preprint. Click to download.

- Supplementarydata.doc 